\title{
Cellulose ethers as water-retaining agents in natural hydraulic lime mortars
}

\author{
Martin Vyšvařil ${ }^{1}$, Patrik Bayer ${ }^{2}$ \\ Faculty of Civil Engineering, Brno University of Technology, Brno, Czech Republic \\ E-mail: ${ }^{1}$ vysvaril.m@fce.vutbr.cz (corresponding author)
}

\begin{abstract}
Cellulose ethers (CEs) are commonly used as viscosity enhancing, water retaining agents in cement-based mortars. Nevertheless, studies about the effect of CEs on the properties of natural hydraulic lime-based mortars (NHL) are absent, although the use of mortars with hydraulic lime is often preferred for renovation purposes. In this study, the behavior of NHL mortars modified by four different CEs is assessed. The fresh state of mortars was characterized by water retention, air content, density a consistency. Hardened mortars were submitted to strength determination, study of pore size distribution, and thermogravimetric analyses. Transport of liquid water in the studied materials was characterized by water absorption coefficient, sorptivity, and liquid water diffusivity. Durability of the prepared mortars was monitored by frost-resistance tests. The results revealed elevated air content and water retention in mortars with increasing dose of CEs resulting in decreased density of fresh mortars. The strengths of modified mortars surpassed the reference ones at age of $180 \mathrm{~d}$ despite the fact that the mortars showed higher open porosity and water absorption. Enhanced porosity of mortars resulted in improvement of their frost resistance and faster carbonation. From a practical and economical point of view, the CEs dosage of $0.5 \%$ by weight of the binder appears to be sufficient.
\end{abstract}

Keywords: natural hydraulic lime, cellulose ethers, water retention, air content, porosity.

\section{Introduction}

Cellulose ethers (CEs) are widely used as additives to improve the quality of dry pre-mixed cement-based materials, self-consolidating concrete especially, and gypsum spray plasters. As admixtures, they improve the plasticity of the mortars and their fresh state adhesion; they eliminate the sagging of mortars by their water-retaining function mostly (Khayat, 1998; Pacheco-Torgal, Ivanov, Karak, \& Jonkers, 2016; Plank, 2004). The most important types of CEs include methyl cellulose (MC), ethyl cellulose (EC), hydroxyethyl cellulose (HEC), hydroxypropyl cellulose (HPC), carboxymethyl cellulose (CMC), hydroxyethyl methyl cellulose (HEMC), and hydroxypropyl methyl cellulose (HPMC). Studies about the effect of CEs on the properties of natural hydraulic lime-based mortars (NHL) are absent, although the use of mortars with hydraulic lime is often preferred for renovation purposes by reason of fulfillment of compatibility requirements with ancient mortars reflected in chemical, physical and structural aspects. In some cases, CEs are added to lime plaster mixtures, and studies of the effect of CEs on air lime mortars are more frequent. Izaguirre et al. (Izaguirre, Lanas, \& Álvarez, 2011) found out that cellulose ethers are much less effective regarding water retention in lime mortars than guar ethers. Seabra et al. (Seabra, Paiva, Labrincha, \& Ferreira, 2009) concluded that HPMC causes easier flowability of lime mortar as air-entrainment agent and lubrication actor. HPMC thus induced a decrease of the relative density of lime mortars. The HPMC also diminishes the durability of lime-based mortars (Izaguirre, Lanas, \& Álvarez, 2010). From the present studies, it seems that the effects of CEs are qualitatively different for limebased mortars and cement-based mortars, so it can be assumed that there will be a difference between the properties of NHL and any of the above-mentioned binders as well. Therefore, the aim of this study is to investigate the influence of CEs on physico-mechanical properties of NHL mortars with emphasis on the differences between the binders.

CEs as water retaining agents can contribute to better hydration of hydraulic components in NHL mortars resulting in improvement of strengths and microstructural properties of mortars. More porous structure of mortars can facilitate the water vapor permeability and the easier salt accumulation from masonry when the mortars are used in remedial works. Increasing number of coarse pores can lead to higher frost resistance of mortars. 


\section{Materials and methods}

The mortar samples were prepared from the NHL 2 (Zement- und Kalkwerke Otterbein GmbH \& Co. KG, DE) according to EN 459-1 and pure quartz sand of fraction 0-2 mm (Filtrační písky, Ltd., Chlum u Doks, CZ). The materials were mixed in a 1:1 volumetric ratio (1:2.2 by weight). The CEs were added in the doses of $0.1 \%, 0.25 \%$, and $0,5 \%$ of the weight of binder. The assayed CEs included HEC (SE Tylose GmbH \& Co. KG, product name: Tylose H 60000 YP2), CMC (Carl Roth GmbH), HPMC (Samsung Fine Chemicals Co. Ltd., product name: Mecellose FMC-21010) and HEMC (Sigma-Aldrich, s.r.o.). These materials were well-mixed to prepare homogenous dry mixtures, which was introduced into the correct amount of water required to obtain the normal consistency and a good workability of the mortars $(160 \pm 5 \mathrm{~mm}$; measured by the flow table test). The proportioning of the mortar mixtures is given in Table 1 . The samples were then cast into $40 \times 40 \times 160 \mathrm{~mm}$ prismatic moulds and demoulded after 48 hours. The beams were stored at ambient conditions $\left(\mathrm{T}=22 \pm 2{ }^{\circ} \mathrm{C}, \mathrm{RH}=50 \pm 5 \%\right.$.) until the day of testing.

The following fresh-state properties of mortars were tested: water retention value (EN 459-2), bulk density of fresh mortar (EN 1015-6), air content of fresh mortar (EN 1015-7). The bulk density of hardened beams, and their flexural and compressive strength (EN 1015-11) were determined at the age of 28, 90 and 180 days. The 180 days old specimens were also used to specify the pore size distribution using high pressure mercury intrusion porosimetry, water absorption coefficient, sorptivity and liquid water diffusivity (EN 1015-18). The water absorption coefficient $\mathrm{A}\left(\mathrm{kg} \mathrm{m}^{2}\right.$ $\mathrm{s}^{-1 / 2}$ ) was calculated from the slope of the straight line of cumulative water weight increments in the sample at square root of time. The sorptivity $\mathrm{S}\left(\mathrm{m} \mathrm{s}^{-1 / 2}\right)$ and liquid water diffusivity $\kappa\left(\mathrm{m}^{2} \mathrm{~s}^{-1}\right)$ were determined according to the literature (Kumaran, 1999). Durability of the prepared mortars was monitored by the frost-resistance test (ČSN 72 2452). The test included 15 freeze-thaw cycles. One cycle consisted of $6 \mathrm{~h}$ freezing at $-20^{\circ} \mathrm{C}$ and $12 \mathrm{~h}$ thawing in water at $20^{\circ} \mathrm{C}$. The frost resistance coefficient $D_{f}$ was determined as the ratio of flexural strength of the specimens subjected to 15 freeze-thaw cycles to flexural strength of the reference specimens that did not undergo the testing. The carbonation rate in mortars were observed using a differential thermal analysis (DTA) in combination with thermogravimetry (TG).

Table 1. Composition of mortar mixtures

\begin{tabular}{|c|c|c|c|c|}
\hline Sample & NHL 2 (g) & Quartz sand (g) & CEs (g) & $\mathrm{H}_{2} \mathrm{O}(\mathrm{ml})$ \\
\hline REF & \multirow{13}{*}{100} & \multirow{13}{*}{220} & 0 & 60 \\
\hline HEC 0.1 & & & \multirow{4}{*}{0.1} & 70 \\
\hline HEMC 0.1 & & & & 70 \\
\hline HPMC 0.1 & & & & 70 \\
\hline СМC 0.1 & & & & 70 \\
\hline HEC 0.25 & & & \multirow{4}{*}{0.25} & 75 \\
\hline HEMC 0.25 & & & & 70 \\
\hline HPMC 0.25 & & & & 75 \\
\hline CMC 0.25 & & & & 70 \\
\hline HEC 0.5 & & & \multirow{4}{*}{0.5} & 75 \\
\hline HEMC 0.5 & & & & 75 \\
\hline HPMC 0.5 & & & & 75 \\
\hline CMC 0.5 & & & & 70 \\
\hline
\end{tabular}

\section{Results and discussion}

\section{Fresh state properties}

Table 2 summarizes the fresh state properties of mortars depending on the CEs dosage rate. As expected, all of the CEs significantly affected water retention and air content in the mortars. Water retention in mortars increased with CEs dosage rate which agrees with previously reported results for cement-based mortars (Cappellari, Daubresse, \& Chaouche, 2013; Spychał, 2015). It should be noted that CEs have a negative effect on water retention in air lime mortars (Izaguirre et al., 2011; Vyšvařil, Hegrová, \& Žižlavský, 2018). All of the prepared mortars with CEs met the standard requirement on water retention which should be higher than $95 \%$ in order to be eligible for commercialization. The incorporation of CEs led to a considerable air content in the mortars which was associated with their reduced density. The percentages of entrained air were higher than in case of air lime mortars (Vyšvařil et al., 2018). The increased air content in mortars could enhance their frost resistance, water vapor permeability, and salt accumulation from masonry. From the point of view of fresh state properties, the CEs seems to be more advantageous in NHL mortars contrary to air lime mortars. 
Table 2. Fresh state properties of mortar mixtures

\begin{tabular}{|l|c|c|c|}
\hline Mixture & Water retention (\%) & Air content (\%) & Density $\left(\mathrm{kg} \mathrm{m}^{-3}\right)$ \\
\hline REF & 81.4 & 2.3 & 1980 \\
\hline HEC 0.1 & 98.7 & 4.4 & 1940 \\
\hline HEC 0.25 & 99.5 & 8.4 & 1900 \\
\hline HEC 0.5 & 100.0 & 9.0 & 1800 \\
\hline HEMC 0.1 & 95.5 & 4.4 & 1920 \\
\hline HEMC 0.25 & 99.2 & 7.9 & 1840 \\
\hline HEMC 0.5 & 99.7 & 12.5 & 1770 \\
\hline HPMC 0.1 & 94.0 & 4.2 & 1930 \\
\hline HPMC 0.25 & 99.1 & 7.7 & 1880 \\
\hline HPMC 0.5 & 99.9 & 12.6 & 1720 \\
\hline CMC 0.1 & 95.8 & 4.0 & 1930 \\
\hline CMC 0.25 & 98.8 & 7.5 & 1900 \\
\hline CMC 0.5 & 99.9 & 12.5 & 1740 \\
\hline
\end{tabular}

\section{Mechanical properties}

The bulk density of mortars with CEs was approx. 15\% lower compared to the bulk density of reference mortar (see Figure 1) due to the higher amount of mixing water and air-entraining function of CEs. The bulk density decreased with increasing dose of CEs. The correlation with the air content in fresh mortars is obvious. After 180 days, the slight enhancing of bulk densities was observed due to the mortars` carbonation.
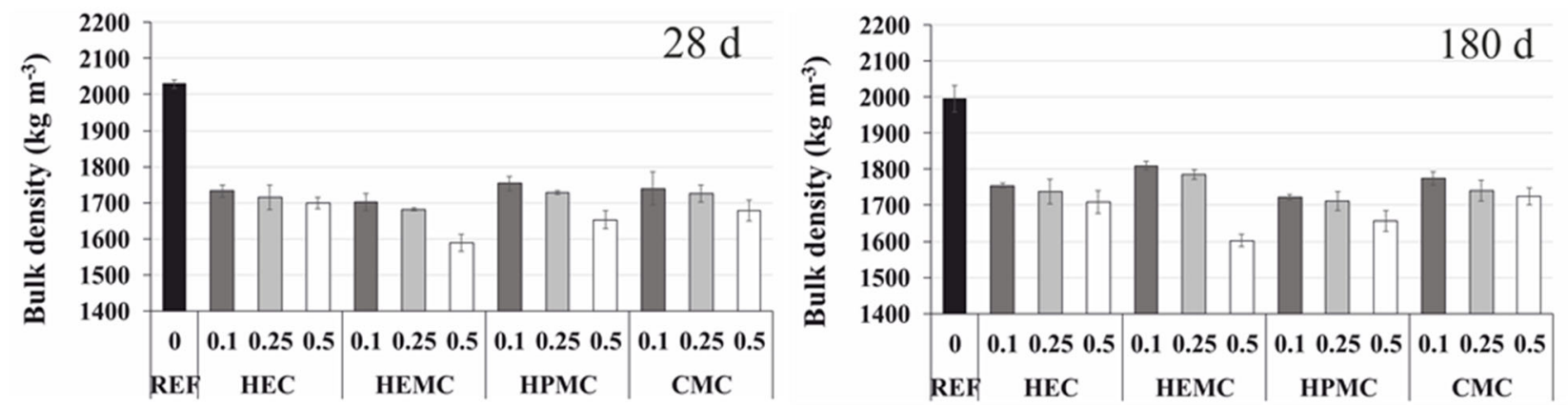

Figure 1. Bulk density of mortars at 28 and 180 days

The strengths test results for ages up to 180 days are compared in Figure 2. It can be seen that the addition of CEs led to a reduction in flexural and compressive strength of the mortars at early ages up to 90 days. A half percent dose of CEs caused a slight increase in strengths at 180 days, despite the higher amount of mixing water required for the same fresh mortar consistency resulted in enlarged porosity of the mortars (Figure 3). This confirmed the fact that the positive effect of CEs on the mechanical properties of mortars will become apparent after a longer period of time. Thus, the development of the strength of cement mortars with the addition of CEs within 28 days tends to apparently unsatisfactory results (Cherop, Kiambi, \& Kosgey, 2017). Similar properties were observed when using chitosan ethers in lime mortars (Žižlavský, Vyšvařil, Bayer, \& Rovnaníková, 2018).

\section{Pore structure}

The results of cumulative pore volume determination in the mortars with $0.1 \%$ and $0.5 \%$ dose of CEs are compared in Figure 3. The addition of CEs caused dramatical growth in porosity and it markedly changed the pore size distribution in the mortars. At $0.1 \%$ CEs dose, the mortars included a significantly higher proportion of pores with a diameter around $1 \mu \mathrm{m}$, the distribution of other pores remained almost the same. An increase in the CEs dose resulted in an enormous growth in the content of pores with the diameter between 1 and $10 \mu \mathrm{m}$. HEC 0.5 and CMC 0.5 samples contained notably more of medium capillary pores with the diameter range $0.01-1 \mu \mathrm{m}$. A narrow pore size range of about $1 \mu \mathrm{m}$ in $0.1 \%$ CEs-dosed mortars has a significant effect on their absorption due to capillarity (see Table 3, Figure 4). The total porosity of mortars (Table 3) expectantly increased with increasing CEs dosage rate and it corresponded to the air content and bulk density of the mortars. 


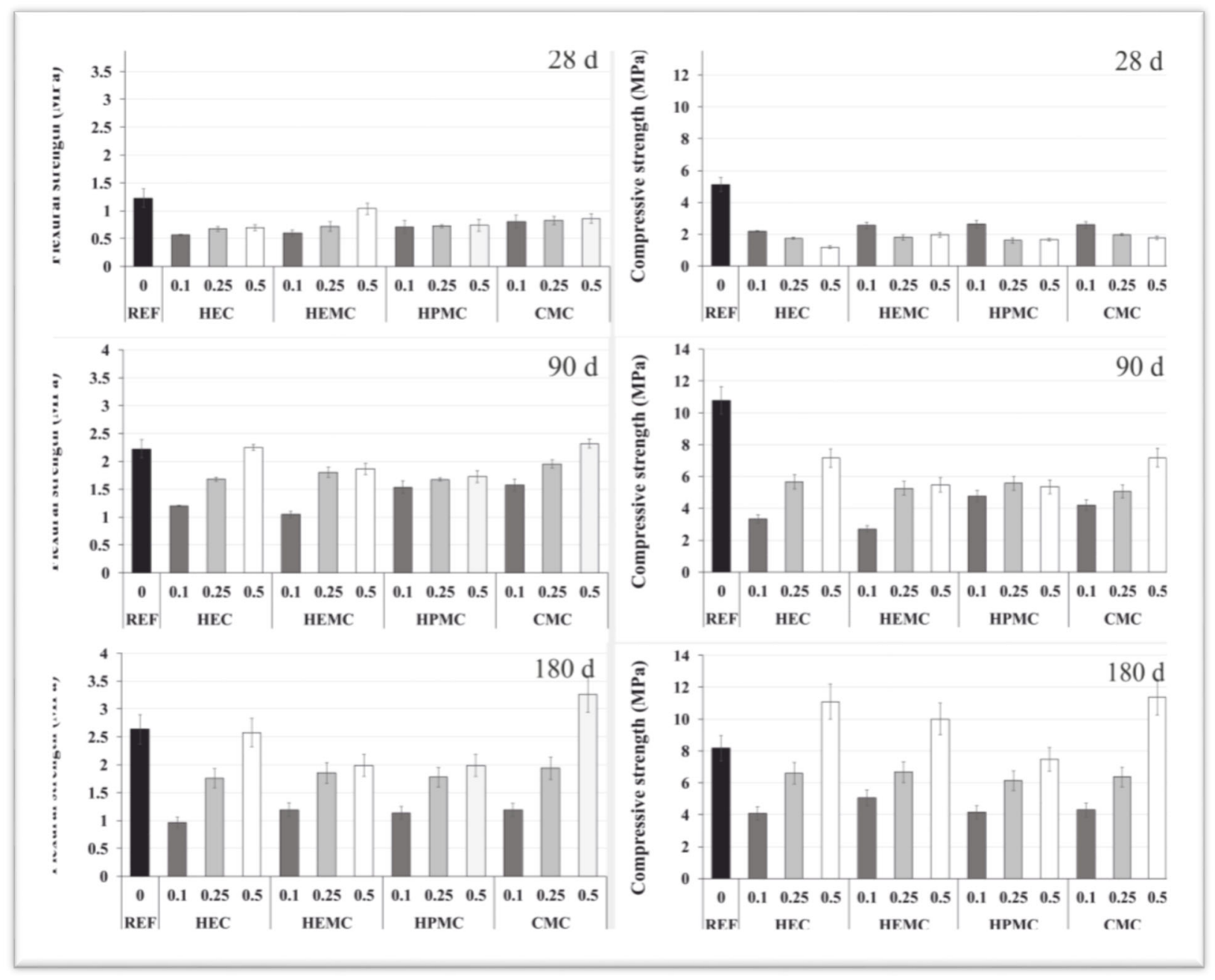

Figure 2. Evolution of flexural and compressive strength of mortars over time
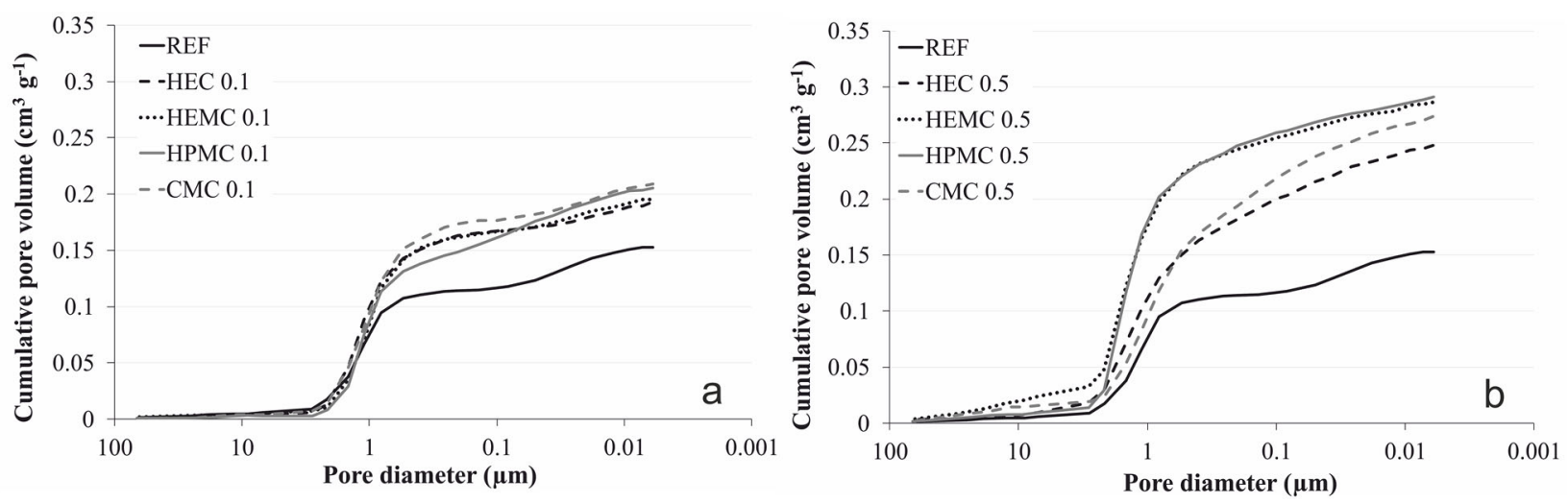

Figure 3. Cumulative pore volume in mortar specimens with $0.1 \%$ (a) and $0.5 \%$ (b) dose of CEs

\section{Water transport}

The water absorption of mortars increased with increasing CEs dosage rate and the mortars with highest total porosity expectantly reached the highest water absorption values (Table 3 ). The mortars with HEC addition have a relatively high water absorption capacity despite the lower total porosity. This fact is probably responsible for the low frost resistance of these mortars (Table 3). Transport of liquid water in the studied mortars by capillary suction was characterized by water absorption coefficient $A$, sorptivity $S$, and liquid water diffusivity $\kappa$ (Table 3 ). The influence of low dose and high dose of CEs was dramatically different. CEs addition in $0.1 \%$ dose brought to the hardened NHL mortars a higher capillarity water absorption compared to non-admixed NHL mortar, which was reflected by higher $A$, 
$\kappa$, and $S$ values. On the other hand, the $0.25 \%$ and $0.5 \%$ dose of CEs caused slower capillary water action in NHL mortars (Table 3, Figure 4). The change in pore size distribution in the mortar structure plays a crucial role in this different capillary water action. Hygric transfers mechanism is a function of the number of air voids (in the diameter range $10-250 \mu \mathrm{m}$ ) and capillary pores (in the diameter range $0.01-1 \mu \mathrm{m}$ ). The increase of number of large capillary pores (with the diameter about $1 \mu \mathrm{m}$ ) in $0.1 \%$ CEs-dosed mortars accelerated the transfer of liquid water. More porous structure of $0.5 \%$ CEs-dosed mortars induced a slowing down of liquid water transfer by reason of specific kinetic regime characterized by slow water vapor diffusion in large air voids assisted by capillary flow in the $0.01-1 \mu \mathrm{m}$ capillaries. The slowing down of liquid water transfer caused by the CEs addition was already observed in cement pastes (J. Pourchez, Ruot, Debayle, E. Pourchez, \& Grosseau, 2010).

Table 3. Total porosity, frost resistance coefficient $\left(D_{f}\right)$ and liquid water transport parameters of mortars

\begin{tabular}{|l|c|c|c|c|c|c|}
\hline Mixture & Total porosity (\%) & Df $(-)$ & Water absorption $(\%)$ & $\mathrm{A}\left(\mathrm{kg} \mathrm{m}^{2} \mathrm{~s}^{-1 / 2}\right)$ & $\kappa\left(\mathrm{m}^{2} \mathrm{~s}^{-1}\right)$ & $\mathrm{S}\left(\mathrm{m} \mathrm{s}^{-1 / 2}\right)$ \\
\hline REF & 28.06 & 0.23 & 14.31 & 0.1343 & $7.188 \mathrm{E}-07$ & $1.35 \mathrm{E}-04$ \\
\hline HEC 0.1 & 33.20 & - & 18.05 & 0.2492 & $2.693 \mathrm{E}-06$ & $2.50 \mathrm{E}-04$ \\
\hline HEC 0.25 & 34.54 & - & 18.81 & 0.1182 & $4.883 \mathrm{E}-07$ & $1.18 \mathrm{E}-04$ \\
\hline HEC 0.5 & 38.15 & - & 22.26 & 0.0777 & $1.798 \mathrm{E}-07$ & $7.79 \mathrm{E}-05$ \\
\hline HEMC 0.1 & 33.47 & 0.28 & 17.34 & 0.3429 & $3.270 \mathrm{E}-06$ & $3.44 \mathrm{E}-04$ \\
\hline HEMC 0.25 & 37.20 & 0.34 & 17.96 & 0.0892 & $2.505 \mathrm{E}-07$ & $8.94 \mathrm{E}-05$ \\
\hline HEMC 0.5 & 41.77 & 0.39 & 19.81 & 0.0721 & $2.053 \mathrm{E}-07$ & $7.22 \mathrm{E}-05$ \\
\hline HPMC 0.1 & 33.74 & 0.24 & 18.00 & 0.2734 & $2.857 \mathrm{E}-06$ & $2.74 \mathrm{E}-04$ \\
\hline HPMC 0.25 & 37.24 & 0.22 & 23.14 & 0.0664 & $2.881 \mathrm{E}-07$ & $6.65 \mathrm{E}-05$ \\
\hline HPMC 0.5 & 42.17 & 0.20 & 23.17 & 0.0540 & $1.552 \mathrm{E}-07$ & $5.41 \mathrm{E}-05$ \\
\hline CMC 0.1 & 34.40 & 0.26 & 17.55 & 0.2710 & $3.139 \mathrm{E}-06$ & $2.72 \mathrm{E}-04$ \\
\hline CMC 0.25 & 35.87 & 0.35 & 18.47 & 0.0753 & $2.335 \mathrm{E}-07$ & $7.55 \mathrm{E}-05$ \\
\hline CMC 0.5 & 40.49 & 0.62 & 19.16 & 0.0836 & $2.852 \mathrm{E}-07$ & $8.38 \mathrm{E}-05$ \\
\hline
\end{tabular}
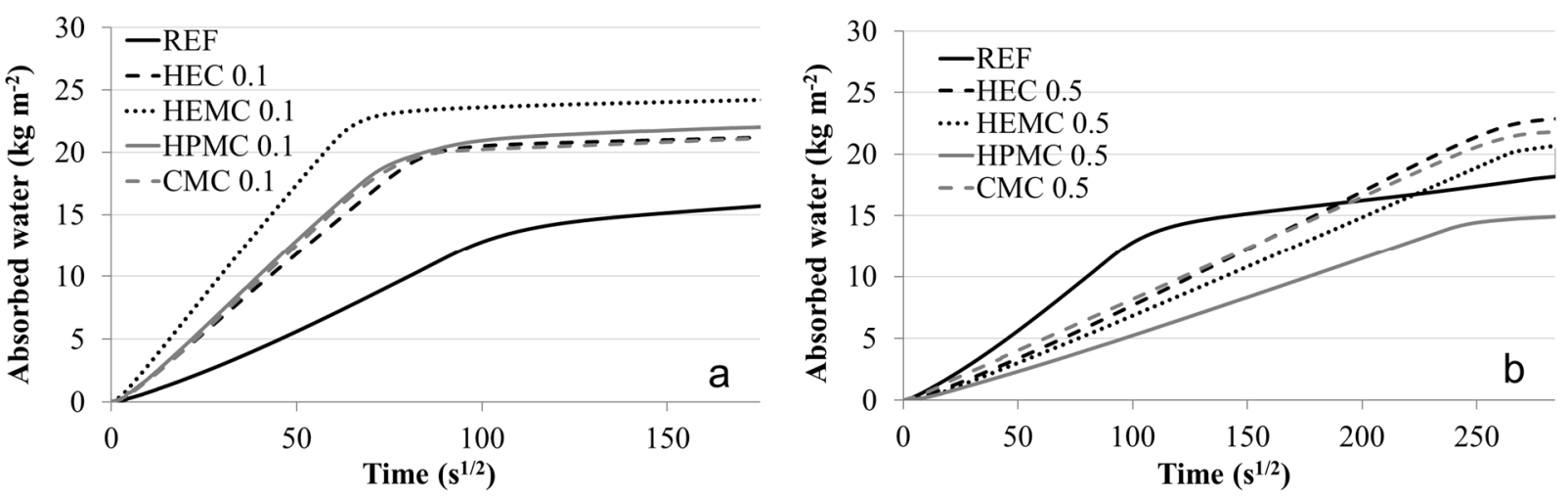

Figure 4. Cumulative mass of capillary water action versus time for mortars with $0.1 \%$ (a) and $0.5 \%$ (b) dose of CEs

\section{Frost resistance}

All of the mortars did not meet the standard criterion of $D_{f}>0.75$ (Table 3), so the mortars cannot be designated as frost resistant (including the reference mortar as well). HEMC and CMC slightly increased the $D_{f}$ for all three doses, which may be due to the lower water absorption of these mortars compared to HEC and HPMC mortars. The addition of all doses of HEC caused the breakdown of mortar samples before the required 15 freeze-thaw cycles. Higher water absorption of the mortars combined with their lower porosity will probably be the reason for such low frost resistance. The absorbed water does not have enough space for a volume increment during ice crystallization, thereby cracks formation and later mortar disintegration occurs. The CMC 0.5 sample was the most frost resistant and, in combination with its other positive results, it appears to be the most suitable for practical use.

\section{Carbonation rate}

The content of portlandite $\left(\mathrm{Ca}(\mathrm{OH})_{2}\right)$ and calcite $\left(\mathrm{CaCO}_{3}\right)$ in the mortars were studied using differential thermal analysis in combination with thermogravimetry (DTA/TG). NHL mortars take a lot of time to reach a total carbonation. After 180 days of curing, a certain amount of portlandite remained uncarbonated in all studied mortars, according to 
the weight loss at $450{ }^{\circ} \mathrm{C}$ in TG results, which indicates $\mathrm{Ca}(\mathrm{OH})_{2}$ dehydroxylation (Figure 5). The content of calcite was converted from the weight loos at $750{ }^{\circ} \mathrm{C}$ in $\mathrm{TG}$ diagrams indicated the decomposition of $\mathrm{CaCO}_{3}$. The difference in percentage representation of portlandite and calcite in the mortars is shown in Figure 6 . The mortars with CEs included at 28 days of storage lower amount of calcite in comparison with the reference mortar but with significantly higher proportion of portlandite. This indicates a slower carbonation rate of these mortars. Slowed carbonation of mortars is one of the reasons for the low mortar strength at 28 days of age. In contrast, after 180 days, the mortars with CEs are more carbonated, which is indicated by higher amount of calcite than in the reference mortar. This is also reflected in the increase in strength. Generally, CEs slows the carbonation of NHL mortars in the early ages, but in the long run, they accelerate the carbonation, mainly by increasing the mortar porosity and facilitating a $\mathrm{CO}_{2}$ diffusion into the mortar structure.

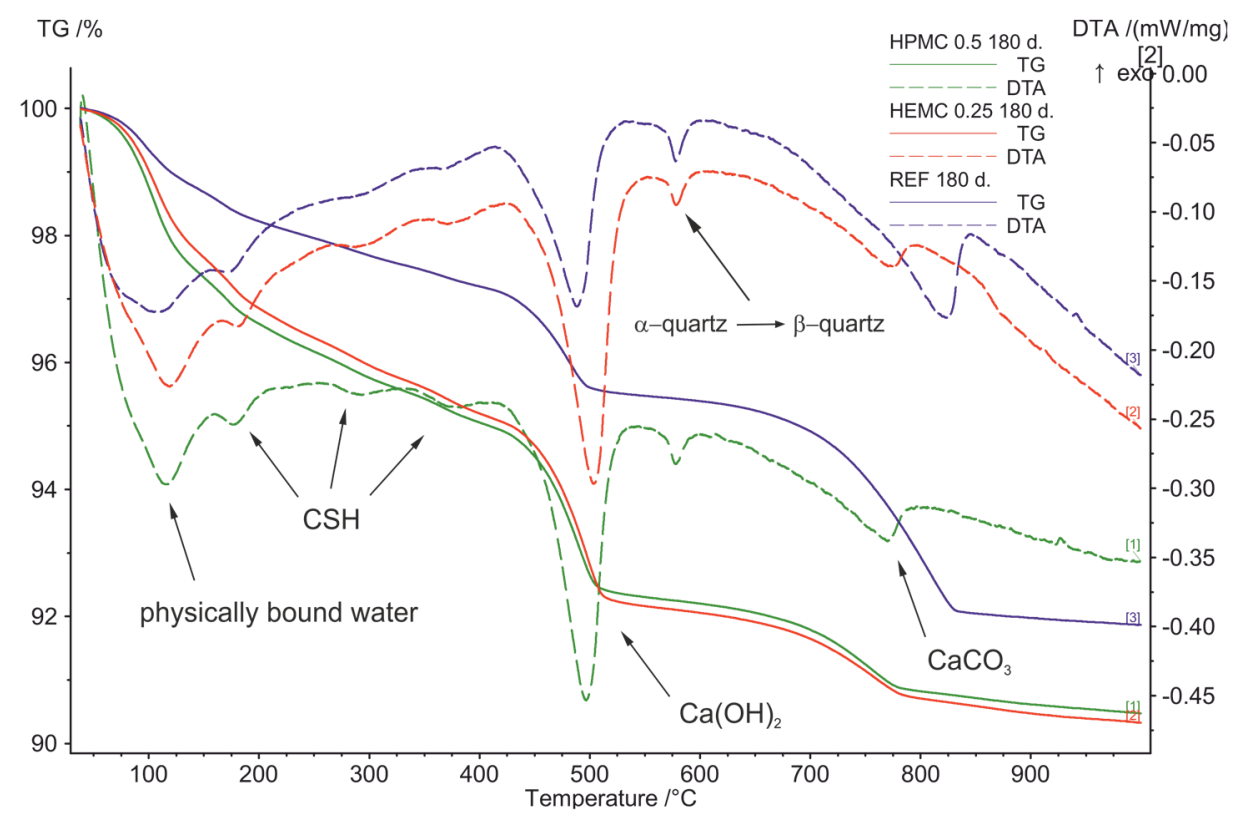

Figure 5. TG/DTA curves of REF, HEMC 0.25, and HPMC 0.5 mortars at 180 days
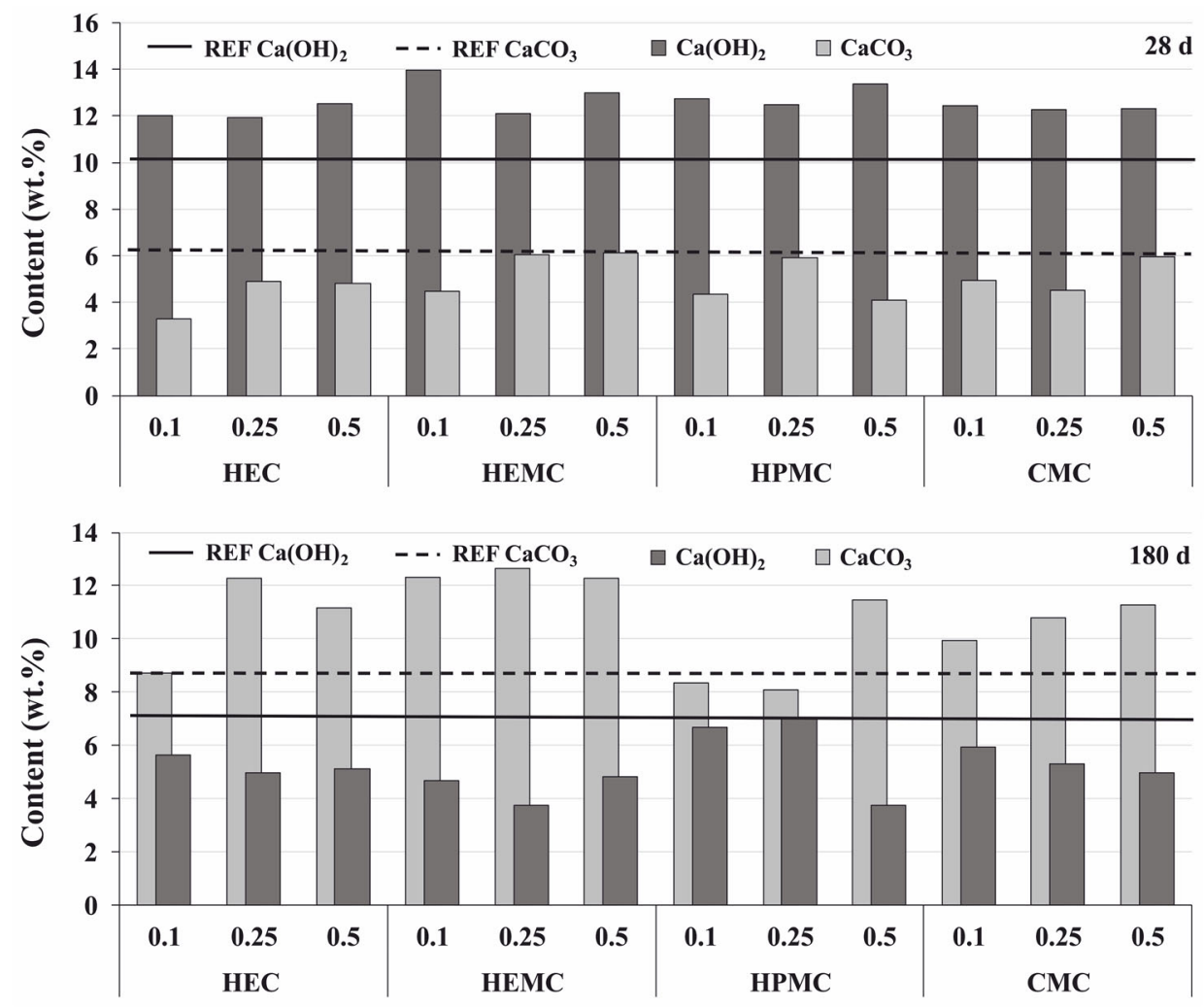

Figure 6. Results of TG/DTA analysis in mortars at 28 and 180 days 


\section{Conclusions}

The paper studies the influence of four different cellulose ethers (CEs) on physico-mechanical properties, microstructure, durability, and liquid water transport of natural hydraulic lime (NHL) mortars. It has been observed that the CEs significantly affect the fresh state properties of NHL mortars by considerable increase in water retention and air content in the mortars. The water retention capacity and air-entraining properties of CEs have a major impact on the resulting properties of hardened NHL mortars. The increasing air content in the mortar and water retention leads to an increase in mortar porosity and changes in pore size distribution, resulting in changes in bulk density, capillary water action, frost resistance, carbonation rate, and strengths of the mortars. The addition of CEs reduces the strength of the early stages of NHL mortar by slowing their carbonation, but the long-term strength of mortars is increased, especially when using $0.5 \%$ of the CEs dose. The increasing dose improves most of the monitored mortar properties but unusually affects the capillary water action. The $0.1 \%$ addition accelerates the liquid water transfer in the NHL mortar, the $0.5 \%$ dose slows down the transfer of liquid water. The change in pore size distribution in mortars causes these differences. The CEs dose plays a crucial role in affecting the properties of NHL mortars. The type of CE used seems to be less important. The use of HEC negatively affects mortar frost resistance due to the combination of higher water absorption and lower mortar porosity. This type of CEs appears to be less suitable for use in NHL mortars.

In general, the effect of CEs on NHL mortars is very similar to that on cement mortars and is different from that on air lime mortars. The capability of some CEs to utilization in NHL mortars has been thus concluded.

\section{Acknowledgements}

This work was supported by the Ministry of Education, Youth and Sports under the "National Sustainability Programme I" [LO1408 - AdMaS UP - Advanced Materials, Structures and Technologies].

\section{References}

Cappellari, M., Daubresse, A., \& Chaouche, M. (2013). Influence of organic thickening admixtures on the rheological properties of mortars: Relationship with water-retention. Construction and Building Materials, 38, 950-961. https://doi.org/10.1016/j.conbuildmat.2012.09.055

Cherop, P. T., Kiambi, S. L., \& Kosgey, E. K. (2017). Effect of non-ionic cellulose ethers on properties of white portland cement, International Journal of Applied Engineering Research, 12(10), 2502-2508.

Izaguirre, A., Lanas, J., \& Álvarez, J. I. (2010). Ageing of lime mortars with admixtures: Durability and strength assessment. Cement and Concrete Research, 40(7), 1081-1095. https://doi.org/10.1016/j.cemconres.2010.02.013

Izaguirre, A., Lanas, J., \& Álvarez, J. I. (2011). Characterization of aerial lime-based mortars modified by the addition of two different water-retaining agents. Cement and Concrete Composites, 33(2), 309-318. https://doi.org/10.1016/j.cemconcomp.2010.09.008

Khayat, K. H. (1998). Viscosity-enhancing admixtures for cement-based materials - an overview. Cement and Concrete Composites, 20(2-3), 171-188. https://doi.org/10.1016/S0958-9465(98)80006-1

Kumaran, M. K. (1999). Moisture diffusivity of building materials from water absorption measurements. Journal of Thermal Envelope and Building Science, 22(4), 349-355. https://doi.org/10.1177/109719639902200409

Pacheco-Torgal, F., Ivanov, V., Karak, N., \& Jonkers, H. (Eds.). (2016). Biopolymers and biotech admixtures for eco-efficient construction materials. Woodhead Publishing: Duxford. https://doi.org/10.1016/B978-0-08-100214-8.00001-4

Plank, J. (2004). Applications of biopolymers and other biotechnological products in building materials. Applied Microbiology and Biotechnology, 66(1), 1-9. https://doi.org/10.1007/s00253-004-1714-3

Pourchez, J., Ruot, B., Debayle, J., Pourchez, E., \& Grosseau, P. (2010). Some aspects of cellulose ethers influence on water transport and porous structure of cement-based materials. Cement and Concrete Research, 40, $242-252$. https://doi.org/10.1016/j.cemconres.2009.09.028

Seabra, M. P., Paiva, H., Labrincha, J. A., \& Ferreira, V. M. (2009). Admixtures effect on fresh state properties of aerial lime based mortars. Construction and Building Materials, 23(2), 1147-1153. https://doi.org/10.1016/j.conbuildmat.2008.06.008

Spychał, E. (2015). The effect of lime and cellulose ether on selected properties of plastering mortar. Procedia Engineering, 108, 324-331. https://doi.org/10.1016/j.proeng.2015.06.154

Vyšvařil, M., Hegrová, M., \& Žižlavský, T. (2018). Influence of cellulose ethers on fresh state properties of lime mortars. Solid State Phenomena, 276, 69-74. https://doi.org/10.4028/www.scientific.net/SSP.276.69

Žižlavský, T., Vyšvařil, M., Bayer, P., \& Rovnaníková, P. (2018). Properties of aerial lime-based mortars with chitosan ethers. Solid State Phenomena, 276, 75-82. https://doi.org/10.4028/www.scientific.net/SSP.276.75 